\title{
Evaluation of efficiency of Sublingual misoprostal and vaginal misoprostal administration for induction of labour
}

\author{
Shivani Singh ${ }^{1, *}$, Hemprabha Gupta ${ }^{2}$, Kumkum Shrivastava $^{3}$, Vasudha Rathi ${ }^{4}$, Uma Gupta $^{5}$ \\ ${ }^{\mathbf{1}}$ Associate Professor, ${ }^{2}$ Professor \& HOD, ${ }^{3}$ Professor Principal, Dean \& CMS, ${ }^{4}$ Junior Resident, ${ }^{5}$ Professor, Dept. of Obstetrics \\ and Gynecology, Era's Lucknow Medical College \& Hospital, Lucknow, Uttar Pradesh, India
}

*Corresponding Author:

Email: bundela.shivani@gmail.com

\begin{abstract}
Objective: To determine the efficacy and safety of misoprostol administered sublingually and vaginally for induction of labour. Material and Method: A randomized control trial was conducted on antenatal women for 18 month period from 1 st Jan 2015 30th June 2016 admitted to Obstetrics \& Gynaecology department of Era's Lucknow Medical College and Hospital Lucknow. Total 120 antenatal women of 37 weeks or more gestational age fulfilling the inclusion criteria were enrolled in the study and they were randomly divided in to two groups (60 women in each group) sublingual group where they received 25 microgram misoprostol sub lingual and vaginal group where 25 microgram of misoprostol was administered per vaginally .Same dose was repeated every four hour until 3 or more uterine contraction of $40 \mathrm{sec}$ duration occur over 10 minutes, or when a maximum of six doses i,e 150 microgram was reached and labour outcome was noted.

Result: In our study the mean induction -delivery interval in sub lingual group was 13.28 hour and12.96 hour in vaginal group. The rate of caesarean section in the sublingual group was31.7\% and invaginal group it was found to be $20 \%$. However, it was not statistically significant. No significant side effect of misoprostol was seen during the study.

Conclusion: Sublingual route of misoprostol administration is as efficacious and safe as vaginal route for induction of labour.
\end{abstract}

Keywords: Misoprostol, Caesarean section, Labour.

\section{Introduction}

Induction of labour is the artificial initiation of labour before its spontaneous onset to deliver the fetoplacental unit. The World Health Organization (WHO) Global Survey on Maternal and Perinatal Health, between 2004 and 2008, conducted in 24 countries which included nearly 3,00,000 observations, showed that $9.6 \%$ of them were delivered by induced labor. ${ }^{1}$ There are several effective methods for cervix ripening which include prostaglandins, antiprogestins, nitric oxide donors, etc. Among many proper and effective methods for cervical ripening, there is still no agreement on which method is the best for labor induction of cases with unripe cervix. The goal of induction is to achieve a successful vaginal delivery that is as natural as possible. Misoprostol (Cytotec, Searle, Illinois, USA) is a methyl ester of prostaglandin El additionally methylated at C-16. It is marketed for use in the prevention and treatment of peptic ulcer disease caused by prostaglandin synthetase inhibitors. In addition, misoprostol acts as an effective myometrial stimulant of the pregnant uterus, selectively binding to EP-2EP-3 prostanoid receptors. ${ }^{2}$ The drug is inexpensive, easily stored at room temperature and has few systemic side effects. It can be administered via several routes (oral, vaginal, sublingual, buccal). Recent evidence has shown that in most of cases a sublingual dose of 50 microgram every 4 hours can induce vaginal delivery within 24 hours and requires lesser oxytocin augmentation as compared to oral dose. ${ }^{3}$

Considering the fact that Misoprostol can be administered through several routes, the present study was planned to compare two routes, i.e. vaginal and sublingual routes for induction of labour using an equal dose $(25 \mu \mathrm{g})$ in order to determine their relative efficacy.

\section{Material and Methods}

This is a randomized clinical trial of 18 months period from January 2015 to June, 2016 conducted on antenatal women of gestational age 37 weeks or more admitted to the Obstetrics \& Gynaecology department of Era's Lucknow Medical College and Hospital, Lucknow Total 120 antenatal women were enrolled in the study and they were randomly allocated into two groups, sublingual group and vaginal group, 60 women in each group.

The inclusion criteria included single, live pregnancy of more than 37 weeks in cephalic presentation with fetal weight less than 4000 grams, amniotic fluid index greater than $5 \mathrm{~cm}$ and normal antepartum non stress test results.

Women with fetal malformations, intrauterine growth restriction, previous uterine surgeries, suffering from respiratory or cardiac disease or hypersensitive to misoprostol were excluded from the study. After informed and written consent the participant who received sublingual misoprostol were asked to keep the tablet under the tongue and not to swallow the tablet at least for 20 minutes. The patients who received vaginal misoprostol were asked not to stand up or move around after the insertion of vaginal tablet. The administration was repeated every 4 hours until 3 or more uterine contractions of 40 seconds duration occur over 10 
minutes, or when a maximum of 6 doses i.e. 150 microgram was reached. In cases of absence of either of these two criteria mentioned above, failed induction was reported and caesarean section was undertaken.

All laboring women were monitored for fetal heart rate, uterine contractions and progress of labor. Maternal adverse effects included abnormal uterine contractions, GIT symptoms, hyperpyrexia and perinatal outcome was done by analyzing FHR changes during labor, intrapartum passage of meconium, Apgar scores at 1 and 5 minutes and newborn admission in NICU.

\section{Statistical Analysis}

The statistical analysis collected was subjected to analysis using Statistical Package for Social Sciences, version 15.0 and then compared with Chi Square test and Student ' $t$ ' test for comparison of qualitative data. After check of normality, Mann Whitney and KruskalWallis test were used, if normality not fitted, Independent t-test and ANOVA test used if normality fitted to data. p- value less than 0.05 was considered statistically significant.

\section{Ethical Considerations}

The study was done after obtaining clearance from the institutional ethical committee of Era medical college and hospital.

\section{Result}

The antenatal women were matched for age, parity and gestational age in both the groups and all were comparable. Fever was seen in 2 women $(3.3 \%)$ in the sublingual group and 4 women $(6.7 \%)$ in the vaginal group. Three women $(5 \%)$ of the sublingual group also reported vomiting. No case of uterine hypersensitivity or tachysystole was seen in either of two groups. (Table 1) The rate of cesarean section in the sublingual group was $31.7 \%$ and $20 \%$ in the vaginal groups. Although cesarean rate was higher in women of the sublingual group as compared to the women of vaginal group. There was no statistically significant difference was found between the two groups $(\mathrm{p}=0.144)$ (Table 2). Majority of cases in both the groups required four to five doses of misoprostol for successful vaginal delivery. Only 3 women in the sublingual group and 4 women in the vaginal group required 6 doses of misoprostol for vaginal delivery. Statistically, this difference was not significant. $(\mathrm{p}=0.101)$ (Table 3).

The Mean of induction delivery interval in sublingual group was 13.28 hours and 12.96 hours in vaginal group respectively. On comparing the duration between two groups, this difference was not statistically different. ( $\mathrm{p}=0.600)$ (Table 4) In the sublingual group, 10 women $(58.82 \%)$ had cesarean section for nonprogress of labor (NPOL), 7 women had cesarean section for $(41.18 \%)$ MSL and non assuring fetal heart rate.

In the vaginal group, 8 women $(57.1 \%)$ had NPOL and 6 women $(42.8 \%)$ had MSL with non assuring fetal heart rate respectively.

Statistically, no significant difference was found between two groups with respect to different indications for cesarean delivery.(Table 5) Fetal outcome was reasonably good and there was no life threatening effect on the babies. Only $1(1.7 \%)$ case, in each group had Apgar score between 5-7. None of the babies had APGAR score < 5. All the other babies $(n=59 ; 98.3 \%$ in each group) had APGAR score $\geq 7$. Statistically, it was not significant $(p=1)$ (Table 6). One baby in each, group had birth asphyxia (APGAR<7). No other fetal complication, viz. meconium aspiration, neonatal jaundice or ARDS was seen in any of the two groups.

Table 1: Distribution of cases according to side effects of Misoprostol seen in mothers in both groups

\begin{tabular}{|c|l|c|c|c|c|c|c|}
\hline \multirow{2}{*}{ S. N. } & \multirow{2}{*}{ Side Effect } & \multicolumn{2}{c|}{$\begin{array}{c}\text { Sublingual } \\
(\mathbf{n = 6 0})\end{array}$} & \multicolumn{2}{c|}{ Vaginal (n=60) } & \multicolumn{2}{c|}{$\begin{array}{c}\text { Statistical } \\
\text { significance }\end{array}$} \\
\cline { 3 - 8 } & & $\mathbf{N o .}$ & $\mathbf{\%}$ & No. & $\mathbf{\%}$ & $\boldsymbol{'}^{\mathbf{2}}$ & 'p' \\
\hline 1. & Fever & 2 & 3.3 & 4 & 6.7 & 0.702 & 0.402 \\
\hline 2. & Vomiting & 3 & 5.0 & 0 & 0 & 3.08 & 0.079 \\
\hline 3. & $\begin{array}{l}\text { Uterine } \\
\end{array}$ & & & & & & \\
\hline 4. & hyperstimulation & 0 & 0 & 0 & 0 & - & - \\
\hline
\end{tabular}

Table 2: Distribution of cases according to Mode of Delivery

\begin{tabular}{|c|l|c|c|c|c|}
\hline \multirow{2}{*}{ S. N. } & \multirow{2}{*}{ Mode of Delivery } & \multicolumn{2}{|c|}{ Sublingual (n=60) } & \multicolumn{2}{c|}{ Vaginal (n=60) } \\
\cline { 3 - 6 } & & No. & $\mathbf{\%}$ & No. & \% \\
\hline 1. & Vaginal delivery & 41 & 68.3 & 48 & 80.0 \\
\hline 2. & Cesarean delivery & 19 & 31.7 & 12 & 20.0 \\
\hline
\end{tabular}


Table 3: Distribution of cases according to total number of Misoprostol doses required for successful vaginal deliveries

\begin{tabular}{|c|c|c|c|c|c|}
\hline \multirow{2}{*}{ S. N. } & \multirow{2}{*}{ No. of Doses } & \multicolumn{2}{|c|}{ Sublingual $(\mathbf{n}=\mathbf{4 1})$} & \multicolumn{2}{c|}{ Vaginal $(\mathbf{n}=\mathbf{4 8})$} \\
\cline { 3 - 6 } & & No. & $\mathbf{\%}$ & No. & $\mathbf{\%}$ \\
\hline 1. & One & 1 & 2.4 & 0 & 0.0 \\
\hline 2. & Two & 0 & 0.0 & 6 & 12.5 \\
\hline 3. & Three & 6 & 14.6 & 12 & 25.0 \\
\hline 4. & Four & 17 & 41.5 & 13 & 27.1 \\
\hline 5. & Five & 14 & 34.1 & 13 & 27.1 \\
\hline 6. & Six & 3 & 7.3 & 4 & 8.3 \\
\hline
\end{tabular}

$\chi^{2}=9.220(\mathrm{df}=5) ; \mathrm{p}=0.101$

Table 4: Distribution of cases according to the Induction-Delivery interval between the two groups

\begin{tabular}{|c|l|c|c|c|c|c|c|}
\hline S. N. & \multicolumn{1}{|c|}{ Parameter } & \multicolumn{2}{c|}{$\begin{array}{c}\text { Sublingual } \\
(\mathbf{n = 6 0})\end{array}$} & \multicolumn{2}{c|}{$\begin{array}{c}\text { Vaginal } \\
(\mathbf{n = 6 0})\end{array}$} & \multicolumn{2}{c|}{$\begin{array}{c}\text { Statistical } \\
\text { significance }\end{array}$} \\
\hline & & Mean & SD & Mean & SD & 't' & 'p' \\
\hline 1. & $\begin{array}{l}\text { Induction delivery } \\
\text { interval }\end{array}$ & 13.28 & 4.36 & 12.96 & 3.97 & 0.525 & 0.600 \\
\hline 2. & Latent phase & 8.22 & 2.39 & 8.00 & 2.46 & 0.497 & 0.620 \\
\hline 3. & Active phase & 5.06 & 1.57 & 4.96 & 1.18 & 0.394 & 0.694 \\
\hline
\end{tabular}

Table 5: Distribution of cases according to fetal Indication for C-Section in both groups

\begin{tabular}{|c|l|c|c|c|c|c|c|}
\hline \multirow{2}{*}{ S. N. } & \multicolumn{1}{|c|}{ Indications } & \multicolumn{2}{|c|}{$\begin{array}{c}\text { Sublingual } \\
(\mathbf{n}=17)\end{array}$} & \multicolumn{2}{c|}{ Vaginal (n=14) } & \multicolumn{2}{|c|}{$\begin{array}{c}\text { Statistical } \\
\text { significance }\end{array}$} \\
\cline { 3 - 8 } & & $\mathbf{N o .}$ & $\mathbf{\%}$ & No. & \% & '年, & 'p' \\
\hline 1. & NPOL & 10 & 58.82 & 8 & 57.1 & 0.009 & 0.925 \\
\hline 2. & $\begin{array}{l}\text { MSL + non assuring } \\
\text { fetal heart rate }\end{array}$ & 7 & 41.18 & 6 & 42.8 & 0.009 & 0.925 \\
\hline
\end{tabular}

Table 6: Apgar at Birth

\begin{tabular}{|c|l|c|c|c|c|c|c|}
\hline \multirow{2}{*}{ S. N. } & \multirow{2}{*}{ APGAR } & \multicolumn{2}{|c|}{ Sublingual (n=60) } & \multicolumn{2}{c|}{ Vaginal (n=60) } & \multicolumn{2}{|c|}{$\begin{array}{c}\text { Statistical } \\
\text { significance }\end{array}$} \\
\cline { 3 - 6 } & & No. & \% & No. & \% & ' $\chi^{\mathbf{2}}$ & 'p' \\
\hline 1. & $0-5$ & 0 & 0 & 0 & 0 & & \\
\cline { 1 - 6 } 2. & $5-7$ & 1 & 1.7 & 1 & 1.7 & & \\
\hline 3. & $\geq 7$ & 59 & 98.3 & 59 & 98.3 & 0 & 1 \\
\hline
\end{tabular}

\section{Discussion}

According to World Health Organization, Induction of labour (IOL) needs to be considered when the risk-benefit analysis indicates that delivering the baby is a safer option for the baby and the mother, rather than continuing the pregnancy, and when there are no clear indications for caesarean section and no contraindications for vaginal delivery. ${ }^{4}$ A number of methods are available for induction of labor.

No side effect except for fever in $3.3 \%$ of in sublingual and $6.7 \%$ in the vaginal group was found in our study. Vomiting was noted in $5 \%$ of pregnant women in the sublingual group. Statistically, the difference between two the groups was not significant. Misoprostol is reported to have fewer systemic side effects as compared to other labor inducting drugs (Abdel-Aleem, 2011). ${ }^{5}$

El Kattan et al. (2013). ${ }^{6}$ reported complications like tachysystole in $8 \%$ of sublingual group patients and hypertonus and hyperstimulation in $12 \%$ patients each in sublingual group and $16 \%$ patients each in vaginal group. The rate of side effects is higher with $50 \mu \mathrm{g}$ dose for either of the two routes, as evidenced in the study of Malik et al. (2010) ${ }^{7}$ who found vomiting rate of $10 \%$ in both oral and sublingual groups and tachysystole rate in $2 \%$ of oral and $10 \%$ of sublingual groups. No women in either group had hyperstimulation and hypertonus in our study. The reason for this difference might be attributed to the smaller dose of drug used in the present study. In smaller doses, these side effects are quite low as evidenced in the study of Siwatch et al. (2012) ${ }^{8}$ who reported hyperstimulation and tachysystole in only 1 case each of both subglingual as well as vaginal groups. Thus indicating that $25 \mu \mathrm{g}$ dose of misoprostol administration through either of the two routes does not produce any substantial side effect.

In our study, cesarean delivery rate was $31.7 \%$ in sublingual and $20 \%$ in vaginal groups. However, this difference was not significant statistically. Jahromi et al. (2016). ${ }^{9}$ also reported a lower cesarean delivery rate 
in the vaginal group (14\%) as compared to the sublingual group (22\%) and did not observe a significant difference between two groups which was comparable to our study. Sheela et al. $(2015)^{10}$ and Siwatch et al. $(2012)^{8}$ while using $25 \mu \mathrm{g}$ misoprostol dose reported much lower cesarean delivery rate in both sublingual (14.1\% and $8.7 \%)$ and vaginal $(10 \%$ and $7.5 \%$ ) group, and both of them did not find a significant difference in the route of delivery between the two groups.

In present study we used 25 microgram misoprostol 4 hourly and majority of cases in both the groups required four to five doses of misoprostol. Statistically, there was no significant difference between the two groups with respect to the number of doses required for vaginal delivery. In contrast, Ayati et al. (2014). ${ }^{11}$ used 25 microgram misoprostol 6 hourly, reported need of only two doses in majority of the patients in sublingual group and only one dose in half the patients in vaginal group and showed no significant statistical difference between the two groups.

The mean induction-delivery interval was 13.02 hours in the sublingual group and 12.96 hours in the vaginal group, showing that this interval was longer in the sublingual group as compared to the vaginal group which was not statistically significant. Ayati et al. (2014) [11] in their study reported mean inductiondelivery interval to be $11.62 \pm 6.76$ hours in the sublingual and $11.08 \pm 3.41$ hours in the vaginal group and did not find a significant difference between two routes. El-Kattan et al. $(2013)^{6}$ reported the induction delivery interval to be $10.47 \pm 7.83 \mathrm{hrs}$ in sublingual and $12.04 \pm 7.88 \mathrm{hrs}$ in vaginal group and did not show a significant difference between two routes.

We found that non-progress of labour and meconium stained liquour were the major indications for cesarean section in both the groups. In sublingual group, $63.8 \%$ of caesarean sections were done for NPOL and $31.6 \%$ were done for MSL and fetal distress whereas in vaginal group, $50 \%$ of caesarean sections were done for NPOL and remaining 50\% were done for MSL and fetal distress. Compared to this El-Kattan et al. $(2013)^{6}$ in their study reported fetal distress and failure to start active labor as main indications for cesarean section. However, despite having different indications for cesarean section they also did not report a significant difference in indication for cesarean section between sublingual and vaginal groups. Tayyba et al. $(2013)^{12}$ in their study reported non-progress of labour as one of the two main reasons for cesarean section, while other being fetal distress.

In the present study, only $1(1.7 \%)$ baby in each group had Apgar <7. Compared to this Jahromi et al. $(2016)^{9}$ reported Apgar score $<7$ at 5 minutes in $1 \%$ of babies in the sublingual and $2 \%$ babies in the vaginal group which is not significant. Tayyba et al. $(2013)^{12}$ also found similar number of cases with low Apgar $(<7)$ in both the groups. The Apgar score pattern of present study were in consonance with the findings of ElKattan et al. (2013) ${ }^{6}$ who also reported Apgar $<7$ in 1 case each in both sublingual and vaginal groups.

No neonatal complication was found except for birth asphyxia in one baby each of both the groups. No case of neonatal death, neonatal hyperbilirubinemia, meconium aspiration or acute respiratory distress syndrome was reported in our present study.

El-Kattan et al. $(2013)^{6}$ reported NICU admission for 1 case each in both the groups. All these findings reveal that neonatal complication rate is limited and does not get affected by route of misoprostol administration.

\section{Conclusion}

The present study, thus, showed that sublingual route of Misoprostol administration to be as effective as vaginal route of administration and without adding any additional burden of complication. Thus indicating that the decision regarding route is optional and must be dependent on patient's/obsterician's choice, however, given the variable nature of evidence provided in different studies, the problem needs to be analyzed using a meta-analysis design.

The decision regarding route of administration is optional and must be dependent on patient's / obsterician's choice.

\section{References}

1. WHO Recommendations for Induction of Labour. World Health Organization: Geneva; 2011.

2. Senior J, Marshall K, Sangha R, Clayton JK. In vitro characterisation of prostanoid receptors on human myometrium at term pregnancy. $\mathrm{Br} \mathrm{J}$ Pharm 1993; 108 501-6.

3. Kelly AJ, Kavanagh J, Thomas J. Vaginal prostaglandin (PGE2 and PGF2) for induction of labour at term. Cochrane Database Sys Dev 2003(4):CD003101.

4. Goonewardene M, Rameez MFM, Kaluarachchi A, Perera $\mathrm{H}$. WHO recommendations for induction of labour: RHL commentary (last revised: 1 November 2011). The WHO Reproductive Health Library; Geneva: World Health Organization.

5. Abdel-Aleem H. Misoprostal for cervical ripening and induction of labour: RHL commentary (last revised: 1 May 2011). The WHO Reproductive Health Library; Geneva: World Health Organization.

6. El Kattan, Eman A, Abdel M, Ghada A, Abdel Razek, Abdel Rahman. Sublingual versus vaginal misoprostol for induction of labor in term primigravidas: a randomized study. Evidence Based Women's Health Journal 2013;3(3):111-4.

7. Malik HZ, Khawaja NP, Zahid B, Rehman R. Sublingual versus oral misoprostol for induction of labour in prelabour rupture of membranes at term. J Coll Physicians Surg Pak. 2010 Apr;20(4):242-5.

8. Siwatch S, Kalra J, Bagga R, Jain V. Sublingual vs Vaginal Misoprostol for Labor Induction. J. Postgrad. Med., Edu., Res. 2012;46(3):138-43.

9. Jahromi BN, Poorgholam F, Yousefi G, Salarian L. Sublingual versus Vaginal Misoprostol for the Induction of Labor at Term: A Randomized, Triple-Blind, Placebo- 
Controlled Clinical Trial. Iranian Journal of Medical Sciences. 2016;41(2):79-85.

10. Sheela CN, John C, Preethi R. Comparison of the efficacy and safety of sublingual misoprostol with that of vaginal misoprostol for labour induction at term, Journal of Obstetrics and Gynaecology, 2015;35(5):469.

11. Ayati S, Vahidroodsari F, Farshidi F, Shahabian M, Afzal Aghaee M. Vaginal Versus Sublingual Misoprostol for Labor Induction at Term and Post Term: a Randomized Prospective Study. Iranian Journal of Pharmaceutical Research : IJPR. 2014;13(1):299-304.

12. Tayyba A, Mehreen,Nosheen. Comparison between Sublingual and vaginal misoprostol for labour induction. PJHMS 2013;7(4):1038-41. 